\title{
O protagonismo da mulher a partir da eeologia integral
}

\section{The protagonism of women from the integral ecology}

\author{
Edelcio Serafim Ottaviani* \\ Luiz Albertus Sleutjes**
}

Recebido: 16/10/2017. Aprovado: 02/03/2018.

Resumo: O papel central da mulher, chamada a ser protagonista da família e da paz, interage com a ecologia integral. Essa ideia visa o diálogo entre os fundamentos teológico-bíblicos e os valores éticos. A partir do pensamento autônomo na modernidade, é possível diagnosticar alguns desafios frente à atuação feminina na família e na sociedade. Este texto tem duplo objetivo: a) apresentar a centralidade da mulher na família e na desconstrução da violência; b) ressaltar a fecundidade feminina no desenvolvimento de uma ecologia integral. O método utilizado será o ver, julgar e agir. A partir da experiência atual das famílias e do protagonismo da mulher na história da salvação, propõe-se uma reflexão teológica que vise mostrar o papel central das mulheres na redução da violência na sociedade contemporânea, a fim de favorecer uma tomada de consciência de seu protagonismo ético, fundamental e inspirador para a família e a sociedade do futuro.

Palavras-chave: Ecologia integral. Mulher. Família. Empoderamento.

Abstract: The central role of women, called to be protagonists of family and peace, interacts with integral ecology. This idea aims at the dialogue between the theological-biblical foundations and the ethical values. From the autonomous

Doutor em Filosofia pela Université Catholique de Louvain (UCL, Louvain, 1996). Mestre em Teologia (PUC, São Paulo, 2013). Professor do Departamento de Teologia Fundamental e do Programa de Estudos Pós-graduados em Teologia, ambos da PUCSP. Reitor do Centro Universitário Assunção - UNIFAI.

E-mail:edelcioottaviani@hotmail.com.

** Mestrando em Teologia pela Pontifícia Universidade Católica de São Paulo - PUCSP. Bacharel em Teologia (Pontifícia Universidade de Campinas - PUCCamp, 2011). Licenciatura em Filosofia (Pontifícia Universidade de Campinas - PUCCamp, 2010). Bacharel em Filosofia (Instituto de Filosofia São Tomás de Aquino (INFISTA), São Carlos, 2007).

E-mail: sleutjesla@yahoo.com.br. 
thinking in the modernity, it is possible to diagnose some challenges before the feminine action in the family and in the society. This text has two objectives: a) to present the centrality of women in the family and the deconstruction of violence; b) to emphasize female fertility in the development of an integral ecology. The method used will be to see, judge and act. From the current experience of families and the role of women in the history of salvation, a theological reflection is proposed that aims to show the central role of women in reducing contemporary society violence, in order to promote our awareness of its ethical role, fundamental and inspiring for the family and society of the future.

Keywords: Integral ecology. Woman. Family. Empowerment.

\section{Introdução}

Este texto, ao associar o protagonismo feminino à ecologia integral, caracteriza-se por seu um estudo aditivo e não conjuntivo, ou seja, por desenvolver uma linha de raciocínio que não parte das concepções teológicas já estabelecidas em relação à mulher, mas da situação atual da mulher, a partir de sua experiência concreta e no diálogo com diferentes saberes, em particular com as outras ciências humanas que estudam o papel das mulheres na sociedade atual e o relacionam à ecoteologia integral.

De acordo com Afonso Murad, a ecoteologia não se limita a tratar de temas ambientais, nem se limita à problemática de uma disciplina teológica. No contexto atual, trata-se de repensar a relação dos seres humanos consigo mesmos e com todos os seres que os cercam, a partir de uma perspectiva que não seja eminentemente masculina, ou mais especificamente patriarcal; de um alargamento do campo de visão que permita ao sujeito de conhecimento situar-se numa dimensão planetária e não simplesmente de gênero, em que suas atitudes revelam a consciência de alguém que compreende a interdependência existente em todas as formas de vida na Terra. ${ }^{1}$

Dessa maneira, o presente artigo se desenvolve em quatro momentos importantes. O primeiro momento apresenta o conceito de ecologia integral e seus desdobramentos na relação social. O segundo, caracterizado pelo ver, faz um diagnóstico da sociedade atual, com suas respectivas mutações, bem como do papel da mulher na redução da violência. O terceiro momento, o julgar, expõe alguns pontos importantes das Sagradas Escrituras que ajudam a reconhecer os pontos fracos da cultura patriarcal e machista, assim como vários relatos de libertação feminina. O último, o agir, trata das possibilidades de atuação da mulher na Igreja e no mundo à luz dos princípios da ecologia integral.

MURAD, Afonso (Org.). Ecoteologia: um mosaico. São Paulo: Paulus, 2016. p. 210. 


\section{Ecologia integral e sua relação com o equilíbrio da criação e a paridade entre homem e mulher}

O tema da ecologia integral está estreitamente ligado à justiça e, portanto, aos direitos dos homens e mulheres. Suas raízes estão fixadas na Doutrina Social cristã, elaborada pelos santos padres, pontífices e teólogos, cujas origens estão fixadas no profetismo bíblico e nos Evangelhos. ${ }^{2}$

A preocupação com o presente e o futuro da vida que integra o planeta motiva o Papa Francisco, logo nos primeiros anos de seu pontificado, a inovar no que diz respeito à Doutrina Social da Igreja, uma vez que a Laudato $S i$ 'é a primeira encíclica que trata das questões ecológicas de forma integral. Nas outras ocasiões, a ecologia não foi abordada com abrangência e profundidade. Nela, identifica-se uma grave crise ecológica global e, ao mesmo tempo, convida a todos a atravessá-la numa jornada de conversão ecológica, com o objetivo de cultivar e guardar a vida na casa comum ${ }^{3}$. Parte-se de uma perspectiva holística que busca integrar o ser humano em tudo o que lhe falta: desde a desertificação ambiental, passando pela alienação, até a extinção de todas as formas de violência.

Ao fazer um resgate do caráter efetivo da fé cristã, enquanto ação ecológica, a encíclica lança o questionamento para a humanidade de como será o mundo para as próximas gerações caso nada seja mudado na maneira como os seres humanos hodiernos se relacionam entre si e com a natureza. Nesse sentido, tem-se uma visão sistêmica da realidade que integra ambiente e sociedade, biodiversidade e justiça social ${ }^{4}$. Portanto, essa perspectiva inédita de ecologia integral amplia a compreensão sobre a realidade, compreendendo o ambiente como um locus em que se vivem as dimensões natural, cultural e social do conjunto. Nesse sentido, defender a dignidade feminina é proteger de forma indireta nossa casa comum.

Segundo João Décio Passos, essa postura reformadora de Francisco demonstra uma eclesiologia singular: demostra uma Igreja que assume uma ética pastoral de saída. Em outras palavras, a Igreja não apenas exerce uma experiência de missão, mas é em si toda missionária. Isso se dá à medida

2 ZAMAGNA, Domingos. Doutrina Social da Igreja. In: PASSOS, João Décio; SANCHEZ, Wagner Lopes (Org.). Dicionário do Concílio Vaticano II. São Paulo: Paulus; Paulinas, 2015. p. 310.

3 MALVEZZI, Roberto. Entrevista sobre ecologia com o Papa Francisco. V. 3. Brasília: CNBB, 2016. p. 11.

4 MIRANDA, Mario de França. A reforma de Francisco. São Paulo: Paulinas, 2017. p.100. 
que a ação da Igreja se encarna na realidade com o testemunho servidor do próprio Cristo no devolver a dignidade aos pobres e à natureza. ${ }^{5}$ Dessa forma, pela primeira vez se afirma que o grito dos excluídos compreende o grito da natureza. Assim, esta não se caracteriza como um mero ponto da vida, mas algo ao qual, de alguma forma, estamos integrados. Logo, a realidade natural tem uma integração entre as dimensões humanas e sociais. Dessa forma, a ecologia aparece como um novo princípio moral. ${ }^{6}$

\section{[...] a crise ecológica é uma expressão ou uma manifestação externa da crise ética, cultural e espiritual da modernidade; não podemos iludir-nos de sanar a nossa relação com a natureza e o meio ambiente, sem curar todas as relações humanas fundamentais. ${ }^{7}$}

A encíclica ecológica do Papa Francisco aborda, com todas as letras, a crise ecológica e seus desdobramentos. Essa reflexão sobre a relação da vida ou o paradigma de vida, segundo João Batista Libanio, traz um novo e importante elemento para esse trabalho: a precedência da vida (bios) em todos os seus desdobramentos. A vida traz em si, num primeiro momento, uma organização interna dos diferentes elementos, configurando-se como um movimento orgânico. Isso resulta em funções diferenciadas de interação, que se complementam num sistema. Esse conjunto orgânico ordenado tem dois objetivos fundamentais: o prolongar sua existência por mais tempo possível, mediante a conservação, e o perpetuar-se para além de si. Dessa forma, são duas características: identidade e relação. Não existe um padrão de autossuficiência e sim, um complexo depender da existência mútua: cada ser dá algo de si e recebe algo do outro para viver. ${ }^{8}$ Por outro lado, segundo Libanio, a crise ecológica tem duas faces: uma que concerne a humanidade e outra que diz respeito ao ambiente. Reforça-se, com isso, a ligação entre sustentabilidade e justiça social. O Planeta grita e o pobre, em seus mais variados rostos, entre eles o da mulher, também grita pela vida e pela inclusão. ${ }^{9}$ De acordo com Agenor Brighenti, o Papa Francisco em sua

5 PASSOS, 2015, p. 392.

6 TOSO, Mario. L'encíclica di papa Francesco sull'ambiente. In: Laudato Si': un aiuto alla lettura. Città del Vaticano: Libreria Editrice Vaticana, 2016. p. 35.

7 FRANCISCO, 2015, p. 75, LS 119.

8 LIBANIO, João Batista. Ecologia: vida ou morte? São Paulo: Paulus, 2010. p. 27.

9 LIBANIO, João Batista. The cry of nature in the word of the poor: the case of Brazil. In: PEPPARD, Christiana Z.; VICINI, Andrea (Org.). Just sustainability: technology, ecology, and resource extraction. New York: Orbis Books, 2015. p. 43. 
encíclica Laudato Si' acrescenta à ecologia a noção de integralidade. Somam-se as concepções de ecologia criacional, ambiental, humana, econômica, social, cultural e as da vida cotidiana, assim se alcançam tanto os habitantes da casa, como a própria casa comum. ${ }^{10}$

A ecologia aparece como o adjetivo ambiental. Isso diz respeito ao cuidado com a casa, pois a etimologia da palavra ambiente remete ao giro que o morador dá diante de sua casa, observando-a. Não se trata de um simples movimento, mas de um deslocamento intencional que cuida, capta os detalhes e as mudanças sutis. No entanto, o observado da casa comum não satisfaz os olhos de quem vê, mas lhes preocupa: o ambiente é desfigurado e degradado pela falta de cuidado. Cuidar do ambiente é cuidar da existência humana. Essa tarefa recupera a dignidade tanto de homens e mulheres como parceiros e cooperadores na criação, configurando-se numa mútua valoração.

Outro elemento importante é a ecologia social. A desigualdade social cresce e vitimiza dura e diretamente as mulheres. Por sua vez, a ecologia cultural usa da via da conscientização para defender a natureza e promover algo além do cuidado com o ambiente e a justiça social.

\section{A sociedade atual, mutações e manutenções no papel da mulher (VER)}

A humanidade vive um momento histórico de muitos avanços e alguns recuos. Os progressos acontecem nos campos tecnológicos da comunicação, da saúde e da educação. Todas essas conquistas são para o bem-estar da própria humanidade. Dessa forma, não se pode negar que a situação global tem pontos saudáveis garantidos pela interação entre a técnica e a razão.

Esses progressos, segundo alguns teóricos, não indicam mudanças de uma época, mas antes uma mudança de época. Não obstante, esse desenvolvimento tecnológico não se fez acompanhar de um progresso nas relações humanas, mas em certos casos ele até regrediu. É o que notamos atualmente no Brasil e em outras partes do mundo no que tange

10 BRIGHENTI, Agenor. A evolução do conceito de ecologia no Ensino Social da Igreja. In: MURAD, Afonso; TAVARES, Sinivaldo Silva (Org.). Cuidar da casa comum: chaves de leitura teológicas e pastorais da Laudato Si'. São Paulo: Paulinas, 2016. p. 60. 
a situação da mulher, mantendo a desigualdade entre gêneros e uma escalada da violência e do medo. ${ }^{11}$

Segundo os dados estatísticos apresentados pela organização Compromisso e atitude ${ }^{12}, 35 \%$ das mulheres de todo mundo já sofreram algum tipo de violência física, verbal ou sexual. Em alguns países esse número chega a $70 \%$. Na Índia, ela alcança o índice de $92 \%$. Calcula-se, com base em pesquisa realizada pela ONU, que 50\% das mulheres, vítimas de homicídio em 2012, foram mortas pelos parceiros ou membros da família. Os números de mulheres e meninas juntas somam $70 \%$ do tráfico humano mundial e de cada três vítimas, duas são meninas. ${ }^{13}$

No mesmo sentido, essa mudança de época resulta em um relativismo prático, em uma sociedade líquida que promove relações superficiais, passageiras e supérfluas, como afirma o sociólogo polonês Zygmunt Bauman. Existe uma redução da autoconsciência das misérias, um aumento da insensibilidade para com os limites humanos. Assim, o ser humano faz mal uso do seu poder e compromete a própria liberdade e segurança, pois esse tipo de instabilidade desafia constantemente a justiça e a paz. ${ }^{14}$

É possível constatar que os padrões assumidos são prejudiciais a todas as instituições. Os valores de uma economia de subsistência foram substituídos por outros que favorecem uma economia do desejo. Como consequência, a dignidade da pessoa ganha um novo e reduzido sentido: agora o critério de valorização é o quanto se consome e o quanto se produz. A sociedade de produção e de consumo é aquela em que os sujeitos são transformados em mercadoria, resultando em um verdadeiro desperdício de muitas vidas..$^{15}$

Essa maneira de interpretar a realidade, a partir da perspectiva econômica, da lógica perversa do lucro e do acúmulo de capital, gera sequelas dolorosas à sociedade. São fatores que contribuem para o au-

11 PAPA FRANCISCO. Exortação Apostólica Evangelii Gaudium. São Paulo: Paulus, Loyola. p. 38, EG 52.

12 SANEMATSU, Marisa (Ed.). Portal compromisso e atitude pela lei Maria da Penha. Disponível em: <http://www.compromissoeatitude.org.br/alguns-numeros-sobre-aviolencia-contra-as-mulheres-no-mundo>. Acesso em: 22 jan. 2018.

13 MLAMBO-NGCUKA, Phumzile (Dir.). Un Women. Disponível em: <http://www.unwomen.org/en/what-we-do/ending-violence-against-women/facts-and-figures>. Acesso em: 24 jan. 2018.

14 PAPA FRANCISCO, 2015, p. 67, LS 105.

15 BAUMAN, Zygmunt. Vidas desperdiçadas. Rio de Janeiro: Jorge Zahar, 2005. p. 53. 
mento da desigualdade e seus resultados de violência. Geram arquétipos de homens e mulheres felizes que não condizem com a realidade, ou seja, verdadeiras ilusões que embaçam a visão da pessoa sobre si, o outro e seu contexto.

Pois as excessivas desigualdades econômicas e sociais entre os membros e povos da única família humana, provocam escândalo e são contrárias à justiça social, à equidade, à dignidade da pessoa humana e à paz social e internacional. ${ }^{16}$

No que diz respeito ao campo cultural, os elementos humanos também estão comprometidos. Com isso, cresce a injustiça, o egoísmo e a sociedade adoece. Ou melhor, a Terra toda adoece ${ }^{17}$. A desigualdade gera um ciclo vicioso de violência. ${ }^{18}$ Esses fatores alimentam uma pressa tecnológica, uma deficiência de espera, que exigem das famílias um esforço maior que antes para responder às novas exigências nas relações humanas. ${ }^{19}$

João Carlos Petrini defende a ideia de que todos esses novos fatores da modernidade contribuem negativamente para ecologia integral. Esses elementos acarretam um desequilíbrio no interior das famílias: tanto na relação horizontal que compreende a convivência dos cônjuges, como no sentido vertical de descendência, no que se refere às próximas gerações, e ascendências, na relação entre filhos e pais. Esse desequilíbrio intrafamiliar acaba por se estender ao conjunto da sociedade, acarretando também um desequilíbrio no ecossistema. Uma sociedade desequilibrada, cuja violência é vivida cotidianamente entre os membros de uma mesma família, não desenvolverá uma sensibilidade para perceber a cadeia de violência estabelecida na relação dos seres humanos entre si e dos seres humanos com outras formas de vida.

16 CONCÍLIO VATICANO II, 1962-1965, Vaticano. Constituição Pastoral Gaudium et Spes. 1965. Disponível em: <http://www.vatican.va/archive/hist_councils/ii_vatican_council/ documents/vat-ii_const_19651207_gaudium-et-spes_po.html>. Acesso em: 1 jul. 2015, GS 29 .

17 Cf. OTTAVIANI, Edelcio. Doença, Convalescença e Ascese: o que suporta um corpo. Notas sobre o cuidado coma Mãe Terra, nossa casa comum. In: Cultura Teológica - Revista da Faculdade de Teologia da PUCSP, ano XXIV, n. 87, jan./jun. 2016, p. 202-230. FRANCISCO, p. 42, EG 5.

19 PAPA FRANCISCO. Exortação Apostólica Pós sinodal Amoris Laetitia. São Paulo: Paulus, Loyola, p. 154, AL 275. 
Não é difícil identificar aqueles que frequentemente mais sofrem com essa coação socioeconômica. Eles se encontram nas periferias. São excluídos do sistema porque não correspondem às expectativas e aos estereótipos produzidos na modernidade ${ }^{20}$. Dentre todos os forçados a participar das periferias existenciais, destaca-se a mulher, uma vez que ela aparece como o objeto da mais antiga das relações de dominação: a dominação patriarcal. Desde o início da organização social, os homens moldaram uma sociedade machista, por meio de uma divisão sexual do trabalho em que o homem sai à caça e junto com o alimento traz o poder e a força, o que lhe garante um status quo superior. ${ }^{21}$

Nesse emaranhado de relações, urge repensar o papel da mulher na desconstrução dessa cadeia de violência, uma vez que ela é atualmente uma de suas maiores vítimas. É sabido que um encadeamento de peças muda, quando uma peça é posta fora do seu lugar. Passemos então à leitura da cadeia de violência atual que tem como elemento chave a situação da mulher.

Para fugir da superficialidade ou da ingenuidade quando se fala em protagonismo da mulher, e para não cair no lugar comum de estruturas patriarcais, há dois modos de concebê-lo: negativamente, quando a tomamos como cúmplice da violência e, portanto, reprodutora do ciclo de exclusão; positivamente, quando a vemos como agente da superação da violência e propagadora da paz. De acordo com a especialista em debates de questões de gênero, na Frankfurt University of Applied Sciences, a pesquisadora Michaela Köttig, o protagonismo negativo das mulheres frente à violência se desenvolve de duas formas: ativa e passivamente. ${ }^{22} \mathrm{O}$ primeiro caso se dá quando a mulher se envolve, por exemplo, com o tráfico de drogas, com um grupo neonazista ou com a prática de corrupção, ao ocupar um cargo público. O segundo caso acontece quando a mulher se vê como alvo ou vítima da agressão e, por medo ou por impotência econômica, se cala e não denuncia o agressor

20 TAVARES, Cássia Quelho. A voz das mulheres como interpelação à Teologia Moral: a "Igreja em saída". In: PESSINI, Leo; ZACHARIAS, Ronaldo (Org.). Teologia Moral, fundamentos, desafios, perspectivas. Aparecida: Santuário, 2015. p. 228.

21 SOUZA, Luiz Alberto Gómez. Uma realidade em mutação: a força transformadora dos sujeitos históricos emergentes. In: PESSINI, Leo; ZACHARIAS, Ronaldo (Org.). Ética teológica e transformações sociais: a utopia de uma nova realidade. Aparecida: Santuário, 2014. p. 27.

22 KÖTTIG, Michaela. The causes of violent actions by young women. In: Civitas: revista de ciências sociais. Porto Alegre, v. 16, n. 1, jan./mar. 2016, p. 10-11. 
às autoridades competentes. Essas características se dão independente da condição social ou faixa etária. ${ }^{23}$

O Papa Francisco, em sua exortação sobre a Alegria do Amor, faz algumas ressalvas importantes sobre esse contexto quanto situa a transformação pela qual passa a família e os danos causados à mulher. Dessa forma, ao fazer uma hermenêutica da realidade atual, constata, ao lado de dispositivos antigos, dispositivos inovadores de exploração da mulher

A história carrega os vestígios dos excessos das culturas patriarcais, onde a mulher era considerada um ser de segunda classe, mas recordemos também o fenômeno das "barrigas de aluguel" ou "a instrumentalização e comercialização do corpo feminino na cultura midiática contemporânea". ${ }^{24}$

Todavia, nem tudo compreende apenas situações negativas. No que se diz respeito à esfera jurídica, percebe-se alguns avanços. Comemora-se a conquista na sociedade de alguns instrumentos jurídicos que favorecem a denúncia e o julgamento de situações que depreciam a dignidade feminina. Em 2016, a Lei 11340/06, mais conhecida como Lei Maria da Penha, contra a violência em mulheres, completou uma década em vigor. Não é o ideal, mas um grande começo.

\section{Sagradas Escrituras: tensões entre visões patriarcais e libertadoras com relação à condição da mulher (JULGAR)}

No Antigo e Novo Testamento existem muitos relatos envolvendo mulheres corajosas nas mais diversas situações. Ainda que em não poucas vezes as mulheres estejam envolvidas pela tensão entre a fecundidade e a esterilidade, e por isso sejam colocadas à margem em não poucas situações, as Sagradas Escrituras deixam entrever a centralidade da mulher em vários episódios da história da Salvação.

A centralidade da mulher aparece na tradição bíblica desde o início com Eva, mãe dos viventes (Gn 3,20), tomada como um arquétipo

23 CHACHAM, Alessandra Sampaio; JAYME, Juliana Gonzaga. Violência de gênero, desigualdade social e sexualidade: as experiências de mulheres jovens em Belo Horizonte. Disponível em: <http://revistaseletronicas.pucrs.br/ojs/index.php/civitas/ article/view/21760/14418>. Acesso em: 04 dez. 2017. 
feminino da maternidade que compreende tanto a vida (Abel), quanto a morte (Caim). Eva representa um esboço antropológico da mulher como criatura, como ser que recebe uma atenção especial do Criador, portadora da feminilidade, da maternidade e da liberdade, configurando-se como expressão da força divina que se manifesta ao mundo como ação promotora da vida. Eva é a portadora da alteridade em relação a Adão, o homem. Quando esse reconhecimento do diferente é negado, quando um quer se impor ao outro na forma de razão autoritária e onipotente, o resultado é a morte. Ao primeiro nascido, Deus lhe faz uma única pergunta: onde está o teu irmão? (Cf. Gn Deus pergunta pelo outro. A negação da alteridade, segundo André Wenin ${ }^{25}$, daria o pecado que estaria já na origem. Excluir e marginalizar, são formas subliminares de eliminação do outro.

A fecundidade geradora agentes de vida e não de morte também é expressa pelas matriarcas: Sara, Rebeca, Raquel, Rute, Ester, Lia, Isabel juntamente com outras mulheres que são exemplo de fidelidade ao povo de Deus em meio a contextos adversos. Todas são mães de situações de liberdade que buscam recuperar a comunhão perdida com o Criador e, consequentemente, com todas as criaturas. ${ }^{26}$

Um ícone de resistência em relação àqueles que querem anular a identidade do Povo de Deus, e que merece destaque no Antigo Testamento, é a Mãe dos Macabeus (Cf. 2Mac 7,20-47). Ela é um ícone daquele que sofre e se sacrifica por manter íntegra sua integridade e a de seus filhos frente ao poder despótico do rei selêucida (Antíoco IV Epífanes - ca. 215-162 a.C.) que ocupou Israel e quis lhe impor a cultura e os deuses helênicos. Essa mulher, ao ver seus sete filhos serem martirizados pelo déspota, não aceita o poder vigente da violência, mas testemunha a perseverança na salvação definitiva, em valores promovidos pela cultura semita fiel ao Deus de Israel. ${ }^{27}$ A matrona é modelo de protagonista de uma ecologia integral na medida em que suporta em nome de um momento seguinte de superação, a dor da perda dos filhos sem reagir com vingança

25 Cf. WÉNIN, André. De Adão a Abraão ou errâncias do humano: Leitura de Gênesis, 1,1-12,4. Tradução de João Carlos Nogueira. São Paulo: Loyola, 2011.

26 COSTA, Jonas Nogueira. A fecundidade de Deus: a concepção virginal de Jesus como expressão privilegiada do poder de geração do Espírito Santo. In: VITÓRIO, Jaldemir; GODOY, Manoel (Org.). Tempos do Espírito, inspiração e discernimento. São Paulo: Paulinas; Belo Horizonte: Soter, 2016. p. 138.

27 BíBLIA DO PEREGRINO. São Paulo: Paulus, 1997. p. 1034. 
ou violência. Essa educa para a paz, à fraternidade, à solidariedade e à intergeracionalidade, ao servir de exemplo às gerações futuras.

No Novo Testamento várias são as mulheres que também se destacam pela importância no seguimento de Jesus ou no contato direto com ele nas comunidades judaicas, estrangeiras e no início das primeiras comunidades cristãs. Segundo José Antonio Pagola, Jesus propõe uma nova convivência com as mulheres a qual promove a dignidade e autonomia. ${ }^{28}$

\section{Perspectivas para atuação da mulher na Igreja e no mundo à luz dos princípios da ecologia integral $(A G I R)$}

No tópico 3 pudemos ver como as Sagradas Escrituras, ainda que marcadas por uma leitura patriarcal, não conseguiram apagar o protagonismo das mulheres ao longo da história, deslocado injustamente às periferias da existência. No final do tópico 2, pudemos ver como algumas mulheres - a exemplo de Maria da Penha, patrona da lei que combate a violência contra as mulheres no Brasil - começam a buscar outro lugar, que não é o de submissão ou de posição secundária em relação ao homem, mas o seu lugar de direito, ou seja, o de protagonista de sua própria libertação e de seu respeito como cidadã, cujo direito à isonomia deve ser garantido pela Constituição e reconhecido pelas autoridades militares e civis. No entanto, a teologia moral identifica dois caminhos: um perigoso que justifica a exclusão e outro libertador. O primeiro se dá por meio da ideologia machista que oprime, subjuga e utiliza a mulher, juntamente, com uma espécie de idealismo que difunde estereótipos: "Amélia que era a mulher de verdade", segundo a canção de Mario Lago (1911-2002) e Ataulfo Alves (1909-1969). Já o caminho libertador, faz da mulher protagonista de uma nova realidade.

Neste processo de libertação, a mulher, por sua aliança indestrutivel com a terra, com as fontes da vida, é peça fundamental na luta pelos direitos humanos, pela sua capacidade de superação de tudo que aliena e impede a vida mais plena. ${ }^{29}$

28 PAGOLA, José Antonio. Jesus, aproximação histórica. Petrópolis: Vozes, 2010. p. 255-283.

29 BINGEMER, Maria Clara Luccheti. E a mulher rompeu o silêncio, a propósito do segundo encontro sobre a produção teológica feminina nas igrejas cristãs. In: Perspectiva Teológica, n. 18, 1986. p. 371-381; TAVARES, 2014, p. 237. 
O Papa Francisco em sua exortação sobre uma nova postura de Evangelização que convoca a Igreja à saída reconhece a centralidade da mulher e, ao mesmo tempo, identifica características fundamentais para a desconstrução da violência. Segundo ele, são capacidades peculiares que habitualmente são mais próprias das mulheres do que nos homens.

[...] É preciso ampliar os espaços para uma presença feminina mais incisiva na Igreja. Porque 'o gênero feminino é necessário em todas as expressões da vida social; por isso deve ser garantida a presença das mulheres também no âmbito do trabalho'e nos vários lugares onde se tomam as decisões importantes, tanto na Igreja como nas estruturas sociais. ${ }^{30}$

De acordo com o pensador Paulo Freire, em sua obra, Pedagogia da indignação, as mulheres começaram a ocupar espaços que lhe são de direito. Não há libertação unilateral, só feita por homens ou só por mulheres, mas de comunhão, de integralidade. Dessa forma, a partir de uma perspectiva da ecologia integral e uma abordagem sistêmica, emerge uma nova ética integrando todas as dimensões humanas. Por isso, é importante correr riscos, para romper estruturas impostas e excludentes. ${ }^{31}$

A mudança na agenda de uma nova ética, segundo Leonardo Boff, é urgente e necessária. Ela exige nova posturas diante da crise identificada. Para se chegar à uma ética responsável e como consequência a fecundidade da paz, apresenta seis passos fundamentais: Humanização mínima, vida digna; cidadania, pessoas conscientes que favoreçam unidade na diversidade; justiça societária com resultados de equidade pessoais e sociais; bem-estar humano e ecológico, o que significa cuidado com a qualidade de vida para tudo e todos; respeito às diferenças culturais, respeitando a criatividade; enfim, a reciprocidade e a complementaridade cultural, ou seja, além de respeitar e acolher o outro é preciso partilhar. Esses são pontos de partida para todos os que querem mudança diante da realidade plural, dos desafios e conflitos atuais. ${ }^{32}$

Jürgen Moltmann afirma que Deus criou o ser humano à comunhão. Isso significa a diferença de identidade homem/mulher, no entanto

$30 \quad$ FRANCISCO, 2013, p. 64, EG, 103.

31 FREIRE, Paulo. Pedagogia indignação: cartas pedagógicas e outros escritos. São Paulo: UNESP, 2000. p. 93.

32 BAPTISTA, Paulo Agostinho. Libertação e ecologia, a teologia teoantropocósmica de Leonardo Boff. São Paulo: Paulinas, 2011. p. 260. 
a unidade das gerações, a comunhão dos sexos. Essa interdependência se dá na comunhão com o Cristo e no Espírito. Assim essa relação entre diferentes eleva a humanidade e leva homens e mulheres a um convívio fecundo. Nesses termos, a teologia feminista amplia a reflexão, uma vez que auxilia as mulheres na busca de uma libertação psicossocial, não apenas como destinatárias ou meras ouvintes, mas como protagonistas. ${ }^{33}$

\section{Considerações finais}

O papel central no processo de libertação pertence ao ser humano. Tanto a autonomia quanto o empoderamento não participam da lógica do comércio; não se tatua; independe do traje ou do lugar em que se nasceu. Assim, a mulher não poder ser reduzida a um objeto inerte de ajuda, mas participar como agente de uma nova realidade integral. O diagnóstico e a apresentação de pistas éticas elaborados neste estudo servem a todos, uma vez que a liberdade é essencial, e como essência vem de dentro do pessoal e do coletivo. A liberdade acontece de dentro para fora, não é algo imposto. Logo, esse tema relacionado com a ecologia integral permite pensar uma interdependência entre o masculino e o feminino, entre o particular e o universal e entre o subjetivo e o coletivo. Assim, o feminino integra o masculino em todos os casos; ao contrário, onde essa bipolaridade for separada a vida correrá sérios risco. Não é o sexo que é a referência, mas a pessoa é o critério em si.

Dessa forma, mulheres e homens assumem, cada um com sua diferença, a totalidade das tarefas familiares e públicas. ${ }^{34}$ Primeiro, como proposta de leitura da realidade e de desconstrução de vários preconceitos presentes na sociedade com relação à mulher. Segundo, como diálogo que conduza a uma nova ética integral, possível a partir das qualidades inerentes à humanidade e, consequentemente à mulher: diálogo, escuta, acolhimento, reciprocidade, amorosidade, solidariedade, práxis, serviço e testemunho. Tanto uma quanto outra tarefa pretende incentivar a promoção da vida, de forma integral, a fim de estabelecer novas relações que são alternativas ao modelo descartável.

A fé é testemunho. Dessa forma, essa vivência de tantas figuras femininas na história resultou em fecundidade de paz. Essa pesquisa quer,

33 MOLTMANN, Jürgen. O Espírito da Vida, uma pneumatologia integral. Petrópolis: Vozes, 2010. p. 226.

34 BOFF, Leonardo. Nova era: a civilização planetária. São Paulo: Ática, 1998. p. 73. 
por fim, encorajar o protagonismo da mulher mãe, esposa, filha, cristã, profissional, teólogas e desbravadoras da realidade pastoral e social. São as muitas Marias que, assim como a Mãe misericordiosa de Jesus, cuida do mistério da vida. Esse estudo é apenas um passo na caminhada que visa à compreensão da mulher na centralidade da família e na gestação da vida integral. Esse processo de libertação cuja fecundidade feminina se faz necessária e só será possível a partir de uma ecologia integral, transformando nossa realidade num ambiente mais solidário.

\section{Referências bibliográficas}

BAPTISTA, Paulo Agostinho N. Libertação e ecologia, a teologia teoantropocósmica de Leonardo Boff. São Paulo: Paulinas, 2011.

BAUMAN, Zygmunt. Vidas desperdiçadas. Rio de Janeiro: Jorge Zahar, 2005.

BÍBLIA DO PEREGRINO. São Paulo: Paulus, 1997.

BINGEMER, Maria Clara Luccheti. E a mulher rompeu o silêncio, a propósito do segundo encontro sobre a produção teológica feminina nas igrejas cristãs. In: Perspectiva Teológica, n. 18, 1986, p. 371-381.

BRIGHENTI, Agenor. A evolução do conceito de ecologia no Ensino Social da Igreja. In: MURAD, Afonso; TAVARES, Sinivaldo Silva (Org.). Cuidar da casa comum: chaves de leitura teológicas e pastorais da Laudato Si'. São Paulo: Paulinas, 2016. p. 52-64.

BOFF, Leonardo. Nova era: a civilização planetária. São Paulo: Ática, 1998.

CONCÍLIO VATICANO II, 1962-1965, Vaticano. Constituição Pastoral Gaudium et Spes. 1965. Disponível em: <http://www.vatican.va/archive/ hist_councils/ii_vatican_council/documents/vat-ii_const_19651207_ gaudium-et-spes_po.html $>$. Acesso em: 1 jul. 2015.

COSTA, Jonas Nogueira. A fecundidade de Deus: a concepção virginal de Jesus como expressão privilegiada do poder de geração do Espírito Santo. In: VITÓRIO, Jaldemir; GODOY, Manoel (Org.). Tempos do Espirito, inspiração e discernimento. São Paulo: Paulinas; Belo Horizonte: Soter, 2016.

FREIRE, Paulo. Pedagogia da indignação: cartas pedagógicas e outros escritos. São Paulo: UNESP, 2000. 
GARCIA, Ángel Galindi. Família: globalização, perspectivas e valores à luz da Doutrina Social da Igreja. In: ZACHARIAS, Ronaldo; MANZINI, Rosana (Org.). Magistério e Doutrina Social da Igreja, continuidade e desafios. São Paulo: Paulinas, 2016.

GORDO, Jesús Martínez. Os leigos e o futuro da Igreja, uma revolução silenciosa. Coimbra: Gráfica de Coimbra 2, 2006.

IWASHITA, Pedro K. Maria na teologia simbólica da Patrística. In: Revista de Cultura Teológica. São Paulo. Paulinas, ano XXIV, n. 87, jan./jun. 2016.

KASPER, Walter. A misericórdia, condição fundamental do Evangelho e chave da vida cristã. São Paulo: Loyola, 2015.

LIBANIO, João Batista. Ecologia: vida ou morte? São Paulo: Paulus, 2010.

. The cry of nature in the word of the poor: the case of Brazil. In: PEPPARD, Christiana Z.; VICINI, Andrea (Org.). Just sustainability: technology, ecology, and resource extraction. New York: Orbis Books, 2015. p. 43-45.

MALVEZZI, Roberto. Entrevista sobre ecologia com o Papa Francisco. V. 3. Brasília: CNBB, 2016.

MIRANDA, Mario de França. A reforma de Francisco. São Paulo: Paulinas, 2017.

MLAMBO-NGCUKA, Phumzile (Dir.). Un Women. Disponível em: $<$ http://www.unwomen.org/en/what-we-do/ending-violence-against-women/facts-and-figures $>$. Acesso em: 24 jan. 2018.

MOLTMANN, Jürgen. O Espírito da vida, uma pneumatologia integral. Petrópolis: Vozes, 2010.

. Ética da esperança. Petrópolis: Vozes, 2012

OTTAVIANI, Edelcio. Doença, Convalescença e Ascese: o que suporta um corpo. Notas sobre o cuidado coma Mãe Terra, nossa casa comum. In: Cultura Teológica - Revista da Faculdade de Teologia da PUCSP, ano XXIV, n. 87, jan./jun. 2016, p. 202-230.

PAGOLA, José Antonio. Jesus, uma aproximação histórica. Petrópolis: Vozes, 2010. 
PAPA FRANCISCO. Exortação Apostólica sobre o anúncio do Evangelho no mundo atual Evangelii Gaudium. São Paulo: Paulus, Loyola, 2013. (Acta Apostolicae Sedis 105, 2013, p. 1019-1137).

. Carta Encíclica sobre o cuidado da casa comum Laudato Si'. São Paulo: Paulus, Loyola, 2015. (Acta Apostolicae Sedis 107, 2015).

. Exortação pós-sinodal sobre o amor na família Amoris Laetitia. São Paulo: Paulus, Loyola, 2016. (Acta Apostolicae Sedis 108, 2016).

PETRINI, João Carlos; DIAS, Marcelo Couto. Família no debate cultural e político contemporâneo. São Paulo: Loyola, 2013.

SANEMATSU, Marisa (Ed.). Portal compromisso e atitude pela lei Maria da Penha. Disponível em: $<$ http://www.compromissoeatitude.org. br/alguns-numeros-sobre-aviolencia-contra-as-mulheres-no-mundo $>$. Acesso em: 22 jan. 2018

SOUZA, Luiz Alberto Gómez. Uma realidade em mutação: a força transformadora dos sujeitos históricos emergentes. In: PESSINI, Leo; ZACHARAS, Ronaldo (Org.). Ética teológica e transformações sociais, a utopia de uma nova realidade. Aparecida: Santuário, 2014.

TAVARES, Cássia Quelho. A voz das mulheres como interpelação à Teologia moral: a "Igreja em saída". In: PESSINI, Leo; ZACHARAS, Ronaldo (Org.). Teologia moral, fundamentos, desafios e perspectivas. Aparecida: Santuário. 2015.

TEIXEIRA, José Luiz Sauer. A atuação das mulheres nas primeiras comunidades cristãs. In: Revista de cultura teológica. São Paulo: Paulinas, ano XVIII, n. 72, out./dez. 2010.

TOSO, Mario. L'encíclica di papa Francesco sull'ambiente. In: Laudato $S i$ ': un aiuto alla lettura. Città del Vaticano: Libreria Editrice Vaticana, 2016, p.35.

WÉNIN, André. De Adão a Abraão ou errâncias do humano: Leitura de Gênesis, 1,1-12,4. Tradução de João Carlos Nogueira. São Paulo: Loyola, 2011

ZAMAGNA, Domingos. Doutrina Social da Igreja (verbete). In: PASSOS, João Décio; SANCHEZ, Wagner Lopes (Org.). Dicionário do Concílio Vaticano II. São Paulo: Paulus; Paulinas, 2015. p. 308-312. 